\title{
АУТ-ТЕХНОЛОГИИ: ВОЗМОЖНОСТИ И ОГРАНИЧЕНИЯ. (ВЗГЛЯД С ПОЗИЦИИ HR-MЕНЕДЖЕРА)
}

\author{
Т.Г. ГРИНЕНКО \\ к. филос.н., проф., Северо-Западный институт \\ управления РАНХиГС при Президенте РФ
}

\section{Аннотация:}

В публикуемых научных работах эффективность применения ауттехнологий рассматривается с точки зрения управления затратами. В статье эта проблема рассматривается с позиции управления человеческими ресурсами. Показано, что данные технологии не позволяют в достаточной степени использовать современные методы работы с персоналом, ориентированные на формирование его мотивации, рост профессионализма и компетентность, что ограничивает применение данных технологий.

Ключевые слова: аут-технологии, аутсорсинг, аутстаффинг, оффшоринг, лизинг, уп управление затратами, мотивация персонала, качество, профессионализм, конкурентоспособность.

\section{ВВЕДЕНИЕ}

Применение аут-технологий в отечественном бизнесе в последние годы резко возросло. При этом в современных условиях все более важное значение приобретают данные технологии для оптимизации затрат организации. Поэтому аут-технологии изучаются с позиции экономической выгоды, а исследований о специфике управления персоналом в организациях, применяющих данные технологии, в отечественной науке нет. К аут-технологиям относят аутсорсинг, аутстаффинг, лизинг персонала и, развивающуюся активно в последние годы в мировом бизнесе, технологию оффшоринга.

Аутсорсинг - такое явление, когда многие корпорации стали передавать выполнение отдельных функций внешним поставщикам услуг: сюда относятся, например, обработка данных и юридическая помощь. В научной литературе можно найти ряд определений технологии аутсорсинга. Так, Б.А.Аникин и И.Л.Рудая отмечают, что «аутсорсинг как технология бизнеса состоит в вынесении за пределы компании отдельных функций или видов производственной деятельности (основных, вспомогательных или обслуживающих процессов), выполняемых ранее самостоятельно, либо в реализации «третьей стороной» целых бизнес-процессов, являющихся частью общей бизнес-системы.» [1, с.22] Под бизнес-процессом понимается «совокупность взаимосвязанных функций и видов производственной деятельности, направленных на получение определенного результата» [1, с.22] Хейвуд Д.В. обращает внимание на то, что в отдельную организацию выводится внутреннее подразделение компании и связанные с ним активы и эта организация оказывает компании определенную услугу по 
определенной цене в течение какого-то времени.[3]. Рыбаков Н. отмечает, что это использование ресурсов извне на основе договора для выполнение работы в направлениях, не являющихся для компании-заказчика профессиональной деятельностью. Схожее понимание дает и А.Лазарев. [1, с.62]. А.Ивлев понимает аутсорсинг как «организационное решение, оптимизирующее конфигурацию бизнес-системы, исходя из параметров «качество - издержки - обладание». [1, с.62]. Как видим, прежде всего, речь идет об использовании заемного труда, вернее его результатов. Но и аутстаффинг и лизинг также формы использования заемного труда. Приведенные определения не дают четкого представления, в чем же суть каждой из форм аут-технологий. Аналитики предпринимают попытки развести данные понятия.

\section{РЕЗУЛЬТАТЫ И ИХ ОБСУЖДЕНИЕ}

Аутстаффинг - это кадровая технология, при которой компания, оказывающая услугу или выполняющая определенную работу, оформляет в свой штат уже имеющийся персонал компании-клиента. При этом права и обязанности работодателя переходят к провайдеру услуги, в то время как сами сотрудники продолжают работать на прежнем месте и выполнять свои функции. [4] Значит, основанием для решения является необходимость сокращения затрат на персонал и, следовательно, удешевление себестоимости продукции.

Аутстаффинг позволяет увеличить объем выполняемых работ, предоставляемых услуг и выпускаемой продукции без увеличения штата сотрудников организации, налоговых и иных обязательных отчислений в бюджет и, не усложняя работу кадровой службы и отдела по работе с персоналом. Многие компании применяют аутстаффинг для снижения административных рисков и издержек, связанных с персоналом. Только в США на данный момент аутстаффинг предлагают свыше 2000 компаний, и рынок этих услуг растет в среднем на $35 \%$ ежегодно. Аналогичная ситуация в Западной Европе. Причем, судя по опросам компаний, пользующихся аутстаффингом, основную выгоду для себя они видят в возможности концентрироваться на своем основном бизнесе, не распыляясь на побочные задачи. Компании начинают использовать данную технологию высвобождения персонала обычно в тех случаях, когда имеется определенная непредсказуемость бизнеса, что отражается на загруженности работников, когда есть потребность во временной рабочей силе или слишком велик штат сотрудников. Кроме того, важным является и то, что не нужно рассчитывать зарплату, ходить по судам, общаться с профсоюзами и трудовой инспекцией.

Предпосылками аутстаффинга являются:

- $\quad$ Развитие законодательства в области кадрового учета;

- Сложность и затратность решения административных вопросов трудовых отношений;

- Необходимость гибких организационных структур, что невозможно при большом количестве постоянных сотрудников в штате компании; 
- $\quad$ Стремление к большей свободе и гибкости при разработке «штатного расписания»;

Компании, использующие аутстаффинг, имеют следующие преимущества:

1. сокращение штатной численности персонала при сохранении фактической;

2. использование, когда это необходимо временного персонала;

3. нет необходимости оформлять сотрудников на время испытательного срока;

4. снижение административных и финансовых издержек;

5. обеспечение юридической поддержки при работе с персоналом;

6. возможность сфокусироваться на основной деятельности;

Данные преимущества должны обеспечивать повышение конкурентоспособности компании [5].

Аутсорсинг - это управленческая технология по передаче ранее самостоятельно реализуемых компанией функций внешней компании - исполнителю услуги / работы. В этом случае речь идет не только о сокращении затрат на персонал, а, прежде всего, о специализации выполнения функций, а, следовательно, о повышении качества результата или услуги, и о привлечении к выполнению работы более профессиональных сотрудников. При аутсорсинге предприятие-заказчик покупает непосредственно услугу/работу, а не труд конкретных работников, потому что за его пределы выводится не конкретный персонал, а определенная функция. Кроме того, аутсорсинг позволяет организации гибко реагировать на внешние изменения и внутренние проблемы путем изменения конфигурации организации, перестройки ее структуры.

Лизинг персонала - это его аренда. В этом случае сотрудники работают в штате компании-исполнителя, а оказание услуг фирме-закзчику является лишь частью их функций. Чаще всего заказчик не имеет отношения ни к выбору тех, кто будет непосредственно выполнять работу, ни к организации их труда. К услугам лизинга прибегают во многих случаях, например:

1. появились вакантные места на короткий период (отпуска, больничные, декреты, праздники, командировки и т.п.);

2. есть необходимость в персонале на сезонные работы (в основном, низко-квалифицированные работники);

3. есть необходимость реализовать проект, но нет квалифицированных сотрудников, либо не позволяет численность штата (разработка IT, ведение бухгалтерского учета, маркетинговые исследования, рекламная акция, логистика и т.п.);

4. необходимо минимизировать налоговые потери, исключить затраты на расчет заработанной платы, уменьшить объем административно-кадровой работы (поиск, собеседования, адаптация, мотивация).

Кадровое агентство предлагает услуги своих сотрудников для выполнения работ в компании. Числится сотрудник в штате агентства и получает все необходимые выплаты от агентства в установленном законом порядке. Оффшоринг - передача административных функций, особенно связанных с информацион- 
ными технологиями и телефонией, в развивающиеся страны или третьим лицам внутри страны. [2, с.218-219] Понятие вошло в практику бизнеса и получило действительно широкое распространение. Именно в условиях экономической глобализации разделение труда и производственная кооперация в мировом масштабе открывают совершенно новые перспективы для применения давно известных принципов организации производственной деятельности и управления ею.

Аналитики приводят убедительные доказательства эффективности данных технологий. Данные доказательства можно разделить на две группы: доказательства, основанные на незамедлительной выгоде применения данных технологий и доказательства стратегического характера, основанные на концептуальном подходе к выбору стратегии развития бизнеса.

Первая группа доказательств раскрывает, прежде всего, экономические выгоды предприятия. Основная доля расходов любой организации приходится на оплату труда работников, независимо от того, каким видом деятельности она занимается. Таким образом, самым быстрым способом сократить общие издержки - это либо «урезать» размер окладов работников, либо вообще сократить штат. В первом случае, работники начнут искать себе место с более высокой заработной платой, во втором - увеличившаяся нагрузка вызовет недовольство и дальнейшие увольнения. В этом случае, прежде всего, считают аналитики, выход в применении технологии аутстаффинга. Но позволяет ли эта технология значительно сократить издержки? Организация, в состав которой вошел выведенный за штат персонал, тоже не будет работать себе в убыток. Значит она переложит свои затраты на клиента. Результат труда сотрудников, состоящих в штате компании-работодателя, будет недешево обходиться компании-клиенту. Чтобы решить этот вопрос, компания-работодатель будет вынуждена сокращать зарплату своим сотрудникам. Хорошо, если на рынке труда вакансий по соответствующим специальностям нет. Сотрудники будут вынуждены согласиться с таким предложением, им просто «некуда деться». Но данные действия приведут к формированию скрытого конфликта в организацииработодателе, к демотивации сотрудников, к снижению качества их труда, к негативному отношению сотрудников к прежней компании, как к руководителям, так и к оставшимся работать в этой организации сотрудникам. Чувство обиды и несправедливости будет доминировать в отношениях между людьми, еще вчера работавшими в штате одной компании. (Такая ситуация складывается в организациях, деятельность которых является основным фактором градообразования.) Наиболее компетентные сотрудники будут искать работу с более высокой оплатой труда. Рано или поздно они ее найдут. Тогда компанияработодатель потеряет большую часть профессионалов. Выиграет ли от этого компания, которая вывела их за штат? От того, что она переложила ответственность за результаты работы на другую компанию, ситуация не изменится, если конкуренция на рынке труда низкая. Придется работать с теми, кто остался. Если конкуренция на рынке труда высокая, то произойдет перераспределение компетентных и квалифицированных сотрудников: наиболее подготовленные 
быстро уйдут туда, где больше платят, а если компания-работодатель будет брать профессионалов, то сэкономить не получиться. Будет ли считаться такой аут-проект эффективным? Названные проблемы снимаются, если организация выводит работников за штат в дочерние компании, сохраняя уровень их зарплат и социальный пакет.

Кроме того, после выведения части сотрудников за штат и продолжении с ними трудовых отношений на новой правовой основе принципиально изменится организационная среда в компании. Возникнет дихотомия: свои - чужые. Это отразится на таких важнейших стратегических активах организации, как корпоративная культура, социально-психологический климат, доверие и т.д., снимет синергетический эффект, определяющий эффективность компании, негативно отразится на ее конкурентоспособности. Стремление снизить затраты сегодня может привести к потере рынка завтра. Как видим, данная технология имеет низкий стратегический потенциал. Таким образом, и вторая группа доказательств эффективности аутстафинга весьма относительна. Но это не значит, что аутстаффинг не нужно использовать. Данная технология имеет серьезные ограничения в своем применении, прежде всего, со стороны современных технологий управления человеческими ресурсами, построенных на использовании социально-психологических факторов управления. Но как инструмент гибкого маневрирования в кризисных ситуациях данную технологию использовать необходимо.

Обратимся к технологии лизинга. Рассмотрим эффективность ее применения. Как правило, арендуют персонал в специализированных фирмах или в кадровых агенствах для выполнения временных работ. Так как за результаты труда сотрудников отвечает компания, в штате которой они состоят, то сотрудники, изначально принимающие условия, определяющие их трудовую деятельность, заинтересованы в сохранении своего рабочего места в конкретной организации и стараются выполнять все требования компании-клиента. Реально компания покупает услугу, а вот кто ее будет выполнять - это решение компанииработодателя. Поэтому чем лучше отзываются клиенты о конкретных работниках, тем лучшее предложение этот работник может получить от своих работодателей, которые, в этом случае, выступают как связующее звено между работником и работой. Собственно говоря, лизинговая компания берет на себя от работника функцию поиска работы (на тех условиях, которые устраивают работника: зарплата, режим работы, содержание работы, особые запросы и т.д.) и выполняет функцию поиска и набора персонала, которую ей передает организация-клиент, с соответствующей ответственностью за качество подбора конкретных сотрудников. В этом случае, компания-клиент воспринимается работником не как его трудовой коллектив, а как определенная деловая среда, в которой он осуществляет свои функции. И даже если эта среда его чем-то не устраивает, то проявлять свою активность по ее преобразованию он не только не имеет права, но и обязан найти эффективные формы взаимодействия с данной средой. В противном случае, по инициативе ли компании-клиента, или по собственному желанию, но он покидает рабочее место в компании-клиенте, и, 
как правило, какое-то время находится без работы, пока компания работодатель ищет ему новую работу. Как видим, трудовые отношения, реализуемые при использовании лизинга, отличаются от отношений, складывающихся при использовании аутстаффинга. Нужно отметить, что кадровые технологии в лизинговой компании имеют выраженную специфику: это, прежде всего, быстрая адаптация, которая по силам только достаточно компетентным работникам, модель поведения которых отличается гибкостью, умением работать в разнообразных деловых средах. Таких работников отличает стрессоустойчивость, как правило, внутренний локус контроля, коммуникательность, умение работать в информационно незнакомой среде, а поэтому четкое выполнение инструкций. В своей деятельности они вынуждены большое внимание придавать формальным правилам, требованиям, официальным отношениям. Развитие персонала связано не с должностным или профессиональным продвижением, а с ростом компетентности и становлением репутации. Лизинг - это специфическая форма организации труда персонала, которая дает возможность обеспечить организации квалифицированными (или необходимыми) кадрами для решения неотложных проблем. Экономический эффект от использования лизинга - непрерывная производственная деятельность на достаточном профессиональном уровне, в случае необходимости временной замены отсутствующих работников или выполнения временных работ, и выполнение непредвиденных или требующих высокой квалификации работ силами сотрудников, которых не имеет организация. Стратегический потенциал лизинга невелик: возможность в нужное время привлекать профессионалов для выполнения уникальных работ.

Оффшоринг, как недавно появившаяся и бурно развивающаяся на нашем рынке форма организации не труда персонала, а деятельности фирмы обладает выраженным экономическим и стратегическим эффектом. Но оффшоринг внутри страны развит слабо, в то время, как иностранные компании его используют достаточно широко, в том числе и на отечественном рынке. Не рассматривая глубоко данную форму организации труда, так как серьезных отечественных исследований нет, обратим внимание на то, что при использовании данной формы происходит передача опыта и технологий, что само по себе экономически и стратегически выгодно.

Аутсорсинг представляет собой также форму организации деятельности фирмы и является наиболее распространенной технологией на отечественном рынке аут-технологией. Речь идет не о принятии решения по организации труда персонала, а о принятии решения, прежде всего, по структуре организации, по производственным, управленческим, административным и др. функциям, обеспечивающим деятельность фирмы. Вывод во вне какой-либо функции или бизнес-процесса возможен, как в дочернюю структуру, так и в независимую самостоятельную организацию, так и в функционирующую профильную организацию. Деловые отношения выведенной структуры и основной фирмы имеют в каждом их этих случаев свои особенности. С точки зрения организации работы с персоналом аутсорсинг имеет такие же ограничения, как и аутстаффинг. 
Нельзя не обратить внимание и ряд обстоятельств, которые негативно влияют на применение данных технологий в отечественном бизнесе. Во- первых, эффективность аут-технологий зависит от развитости рынка труда, достаточная конкуренция на рынке труда предоставляет организациям возможность выбора: каких специалистов, с каким уровнем квалификации она хочет иметь. Если же рынок труда низкоконкурентный, то организация теряет свободу выбора и вынуждена работать с тем персоналом, который ей предложит фирмаработодатель. Так как отечественный рынок труда еще недостаточно развит, то при принятии решения об использовании аут-технологий нужно основательно проанализировать рынок труда. Во-вторых, чтобы квалифицированные и компетентные работники не искали новую работу, нужны действенные инструменты их мотивации. Это значит, что фирма-работодатель должна платить достойную зарплату и интересный социальный пакет и заниматься карьерным и профессиональным ростом сотрудников. Но фирмы-работодатели, работающие на основе аут-технологий, не производят продукт, они предоставляют услугу, выражающуюся в предложении персонала для выполнения работы, которая нужна фирме-клиенту. Вопросы карьерного продвижения сразу же отпадают, достойная зарплата зависит, в значительной степени, от соглашения с фирмойклиентом, предоставлять социальный пакет сотрудникам, реально выполняющим работу в другой фирме, компания-работодатель не заинтересована. Мотивация, в основном, зависит от личных интересов человека: желания часто менять рабочее место, относительная независимость от руководства той организации, где осуществляется работа. Поэтому особых стимулов для качественной и ответственной работы у большинства сотрудников, работающих на основе ауттехнологий нет. Конечно, в этом случае есть сотрудники, для которых их репутация - важнейший стимул, но это относится к тем, кто выполняет специфические работы или работы особой важности. Основная же масса сотрудников выполняет обычные функции в, можно сказать, «чужой» организации. Итак, с одной стороны, фирмы и организации заинтересованы в сокращении затрат на персонал, но, с другой стороны, для них крайне важно качество результата своей деятельности и поэтому им нужны высококвалифицированные сотрудники, профессионалы. В настоящих условиях сложно обеспечить данное требование организаций. Если обратить внимание на то, как принимаются решения об использовании аут-технологий $[1$, с.97 - 108], то видно, что и рынок труда, и условия деятельности фирмы как текущие, так и стратегические, анализируются с точки зрения самой организации (например, риски для организации из-за некачественной работы собственной службы персонала [1, с.290-291]) и наличия на рынке труда ряда аутсосеров, предлагающих необходимые услуги. А если аутсорсер один, как, например, при выводе за штат ремонтной службы подвижного состава железной дороги? Тогда эта организация становится монополистом на рынке труда со всеми вытекающими из этого действиями. Почему организация полагает, что проблемы со службой персонала только у нее, а вот аутсорсер может и применяет современные технологии работы с персоналом и, таким образом, обеспечит организацию высококвалифицированными специа- 
листами? Рассмотренные выше вопросы показывают, что это не так. Не нужно затушевывать истинную причину. Главная цель - управление затратами. Это важная проблема, но ее решение зависит и от такого ресурса как персонал, в то время как на специфику управления этим ресурсом совершенно не обращается внимание. При анализе аут-технологий доминирует экономический подход, но и в этом случае комплексный анализ факторов, влияющих на эффективность организации, применяющей аут-технологии, высветил бы проблемы взаимозависимости ресурсов компании. Стратегический менеджмент определяет человеческий ресурс как основной, обеспечивающий конкурентоспособность компании, в то же время анализ работ, опубликованных по проблеме ауттехнологий, показывает, что разработка аут-проектов осуществляется в лучших традициях технократического мышления.

\section{ВЫВОДЫ}

В заключении отметим также и тот факт, что невысокий уровень заработной платы, недостаточная развитость муниципальных социальных услуг делают очень привлекательным для сотрудников те организации, которые могут предложить им решение важнейших личных социальных проблем (детские сады, отдых, здравоохранение, физкультура и спорт, культурное развитие и т.д.) на хорошем уровне и за приемлемую плату. Если организация заинтересована в использовании социальных факторов, как стимулов для профессионального роста и качественной работы, то, сняв с баланса социальную сферу, можно на основе длительных договорных отношений с бывшими «своими» структурами создать более благоприятные условия для сотрудников, обеспечив, таким образом, закрепление квалифицированных работников в организации, даже при снижении их окладов. При принятии решений по применению аут-технологий необходимо принимать во внимание влияние состояния такого ресурса, как персонал, на результаты деятельности организации. Сбалансированный подход, в этом случае, необходимое условие для успешного применений ауттехнологий.

\section{ЛИТЕРАТУРА}

1. Аникин, Б.А. Аутсорсинг и аутстаффинг: высокие технологии менеджмента: Учебн.пособие. 2-е изд., перераб. и доп./ Б.А.Аникин, И.Л.Рудая М.: ИНФРА-М, 2009

2. Коллис, Дэвид Дж. Корпоративная стратегия. Ресурсный подход / Дэвид Дж. Коллис, Синтия А.Монтгомери - М.: ЗАО «Олимп-Бизнес», 2007.

3. Хейвуд, Дж.Б. Аутсрсинг: в поисках конкурентных преимуществ: Пер. с англ./ Дж.Б.Хейвуд - М.: Изд. Дом «Вильямс», 2002

4. www.md-hr.ru/management

5. www.sofia-auditcom.ua 